\title{
Structure and Process in Consociationalism and Federalism
}

\author{
Jürg Steiner \\ University of North Carolina at Chapel Hill and \\ University of Geneva \\ and \\ Robert H. Dorff \\ North Carolina State University at Raleigh
}

\begin{abstract}
It is relatively easy to characterize the institutional structure of a country as consociational or federal. The task is much more difficult if we turn from structure to the decision process. Within a given structure, there may be a great deal of variation with regard to the decision process. Data for such variation are given for the decision process in Switzerland for which the following four types are distinguished: (1) consociational and federal, (2) consociational and unitary, (3) competitive and federal, and (4) competitive and unitary. Difficulties are discussed in aggregating from such a variation to a measure for the prevailing decision process in a country as a whole. It is suggested that the problem be disaggregated and that decision processes be compared for particular issues. This can be done both across and within countries.
\end{abstract}

Within a given institutional structure, one may find a wide variety of decision processes. This is certainly true for consociational and federal structures. The argument of this article is that in talking about consociationalism and federalism, we should distinguish more carefully between structure and process. Much confusion in the literature results from the fact that the degree of consociationalism and federalism in a country is often measured in an indiscriminate way, incorporating both structural and process features. We shall argue that structural and process elements cannot easily be aggregated in a single measure. They require different research methods and, above all, different levels of analysis.

What is the distinction between institutional structures and decision processes? Structure refers to the entirety of written and unwritten rules within which the decision process of a country operates. In the long run, these rules may change, but in the short run, they are relatively stable so that it is appropriate to refer to them as structural elements. The decision process refers to the dynamic day-to-day interactions among the decisionmakers: how they move an issue from arena to arena, the coalitions and bargains they form,

AUTHORS' NOTE: The research on which this article is based was supported by the Swiss National Science Foundation.

Publius: The Journal of Federalism 15 (Spring 1985) ${ }^{\circ}$ CSF Associates, Philadelphia 
the modes with which they make their decisions, and the way they implement these decisions.

In his contribution to this issue, Arend Lijphart limits himself to structural features in order to measure the degree of consociationalism and federalism in a country. As an indicator for consociationalism he uses, for example, the existence of oversized cabinets. Bicameralism is one of the indicators for federalism. It is relatively easy to collect data on such structural features and to reach agreement on the classification of particular countries. As a country expert for Switzerland, Steiner would certainly agree with Lijphart that from a structural perspective, Switzerland can be classified as both a consociational and a federal case. We also do not deny that looking at structural elements has an intrinsic value of its own. There is, for example, research by David Cameron indicating that the degree of federalism measured in structural terms has an influence on the policy outcome. ${ }^{1}$ Thus, analyzing consociationalism and federalism from a structural perspective is a legitimate enterprise.

The pitfalls begin when consociationalism and federalism are measured simultaneously in structural and process terms, which is unfortunately the common pattern in the literature. The classification of particular countries then proceeds typically in the following manner: unsystematically chosen case studies of decision processes are used to reinforce the classifications based on structural data. This procedure would be appropriate if structure fully determined process. Under these circumstances, it would indeed be sufficient to deal with the process simply by providing some colorful illustrations. If, for example, a country had a grand coalition and other structural features of consociationalism, it would be sufficient to illustrate how this structure is translated into the decision process through the use of a few examples.

But structure does not automatically translate into process. This point is eloquently made in the articles by Ivo D. Duchacek and Daniel J. Elazar. The latter argues with regard to federalism that "many polities with federal structures were not all that federal in practice."'2 Duchacek states that the "admixture" of consociational and competitive decision modes may be different "at different times on different issues." 3 We can now present some new Swiss data, which support these general claims. The data are based on interviews with 203 members of pre-parliamentary expert committees. ${ }^{4}$ These committees are considered a key structural element of Swiss consociationalism and federalism. ${ }^{5}$ From a consociational perspective, it is im-

\footnotetext{
'David R. Cameron, "The Expansion of the Public Economy: A Comparative Analysis," The American Political Science Review 72 (December 1978): 1243-1261.

${ }^{2}$ Elazar, pp. 17-34.

${ }^{3}$ Duchacek, pp. 35-48.

${ }^{4}$ For more information on the data base, see Raimund E. Germann and Jürg Steiner, "Comparing Decision Modes at the Country Level," British Journal of Political Science 15 (January 1985): 123-126.

${ }_{5}^{5}$ Jürg Steiner, Amicable Agreement Versus Majority Rule: Conflict Resolution in Switzerland (Chapel Hill: University of North Carolina Press, 1974).
} 
portant that all interested groups are usually represented in these expert committees. To be an "expert" in this context mainly implies being knowledgeable about the interests of particular groups. From a federal view, it must be noted that the cantons are always included among the interest groups represented in the expert committees. It is a constitutional stipulation that the Confederation must hear the views of the cantons in this phase of the decision process.

Do these consociational and federal structural features of the expert committees also mean that the decision process in these committees is of a consociational and federal nature? Initial case studies seemed to give a positive answer. Steiner conducted a study of an expert committee, which dealt with the question of federal subsidies to cantonal universities. ${ }^{6}$ Through participant observation, he determined that during more than two years of committee deliberations, conflicts were resolved by a majority vote only a single time. Mutually acceptable compromises were reached in all other instances. Furthermore, committee members often spoke as representatives of their cantons.

Some recent case studies raise questions concerning the extent to which the findings about this university expert committee have general validity. In order to get a broader overview of the situation, Germann and Steiner undertook the above mentioned interview survey of a representative sample of expert committee members. The results show a surprising variation in the way Swiss expert committees handle their internal decisionmaking process. Recall data have obvious weaknesses, primarily due to faulty memories and outright distortions. We have dealt with this methodological problem in another paper. ${ }^{7}$ In the present context, the exact figures are less important than the overall impression of a significant amount of variation in the interview responses. One can certainly not infer from these data that consociationalism and federalism clearly dominate the decision process in Swiss expert committees.

We look first at consociationalism. Asked how often consociational and competitive decision modes are used, the committee members mentioned majority decisions slightly more often than consensus. Fifty-three percent of the respondents said that it occurs "always" or "often" in their committees that "a vote is taken and the proposal which gets a majority becomes the decision." Forty-three percent answered that it happens "always" or "often" in their deliberations that "the proposals are debated until one of the proposals gets the explicit approval of all members." These data may be biased in one direction or the other, but it would be impossible to make a case that amicable agreement is the dominant decision mode in Swiss expert committees. This conclusion is reinforced if we look at the categories "rarely" and "never," omitting the middle category "sometimes." A surprisingly high number (29 percent) said that they "rarely" or "never" reach consensus in

${ }^{6}$ Steiner, Amicable Agreement Versus Majority Rule, pp. 129-165.

${ }^{7}$ Germann and Steiner, "Comparing Decision Modes at the Country Level." 
their committees. This figure certainly does not square with the notion that Swiss expert committees operate mostly by amicable agreement. ${ }^{8}$

The findings are also ambivalent with regard to federalism. There is no clear support for the claim that cantons are always important actors in the decision process, although they are formally represented in all committees. According to our interviews, only 7 percent of the respondents see themselves primarily as representatives of a canton. In order to understand this figure, one must know that in Switzerland most politicians accumulate several political roles. Thus, a member of an expert committee, who was appointed as a representative of a canton, is also likely to have important roles in a political party and various interest groups. Involved in the daily decision process of an expert committee, such a person may very well attach low importance to his cantonal role and high importance to some of his other roles. It may even be that he has literally forgotten in which role he was originally appointed to the committee, especially if this appointment occurred some years back. Contributing to this uncertainty is the fact that sometimes persons are appointed in several roles to an expert committee. It also happens that an appointment is made without a clear specification of the exact interest which the committee member is supposed to represent. This discussion should indicate that it is not sufficient to look at the structural composition of Swiss expert committees. We must also see how the roles are defined in the actual decision process. From this perspective, the cantons seem to have less importance than one would expect from the structural features of the committees. There are obviously many issues in Swiss expert committees in which the cantons have no clearcut interests and therefore do not appear as principal actors.

Summarizing with regard to both consociationalism and federalism, it seems that we can identify the following four types of decision processes in Swiss expert committees: (1) consociational and federal, (2) consociational and unitary, (3) competitive and federal, (4) competitive and unitary. Thus, we have substantial variation in a given structural arrangement. Clearly, structure is not automatically translated into process. We agree with Elazar's argument that we must distinguish between a process and a structural dimension. This is what he does in his Figure 4 for federalism. On the one hand, for structure, and on the other hand, for process, he classifies a large number of countries along a federal-unitary dimension. According to this classification, France has both a unitary structure and unitary process, Israel a unitary structure but a federal process, the USSR a federal structure but a unitary process, and Switzerland both a federal structure and process. We have no problems with the classification on the structural dimension. But we are uneasy about the process dimension. Elazar acknowledges that "we know

\footnotetext{
${ }^{8}$ Besides majority decisions and amicable agreement "decisions by interpretation" were another frequently used decision mode for which we refer to another publication: Jürg Steiner and Robert H. Dorff, "Decision by Interpretation: A New Concept for an Often Overlooked Decision Mode," British Journal of Political Science 10 (January 1980): 1-13.
} 
relatively little about federal processes." The classifications are called "tentative" and "based on assessment of currently available evidence." For Switzerland at least, there are many different ways to interpret the available evidence. As more data become available, it becomes less clear as to how much Swiss decision processes are federal or unitary. Sometimes the cantons are important actors, but often they are not. The main impression is the great amount of variation from one decision process to another. The same is true if we try to classify the overall decision processes as competitive or consociational.

How can we arrive at a more systematic and reliable classification on the process dimension for both federalism and consociationalism? Relying on recall data, such as those presented in this article, will not be sufficient because the potential distortions are simply too large. ${ }^{10} \mathrm{~A}$ more promising approach would be to study a representative sample of actual decision cases. The practical difficulties of such an enterprise are, however, so formidable that we are now less optimistic than in an earlier publication. ${ }^{11}$ At first, we would have to determine the universe of all decision cases from which a representative sample could be drawn. This would presuppose that we define in a clear way what we mean exactly by a decision case. How broad or how narrow should the definition be? Is, for example, the nuclear construction program of a country a single case, or should we consider the construction of each individual reactor as a separate case? We would also have to deal with the question of the time period to which the sample of decision cases should refer. Would five years or ten years be appropriate time spans? We would further have to come to terms with the problem that some decision cases are obviously of greater importance than others. This would mean that we would have to attach different weights to the various cases. In principle, all these problems may seem solvable. But having tried to take some steps in this research direction, we now realize that the task is so formidable and the resources so limited that it seems practically impossible to execute such a project. We would need dozens, perhaps hundreds, of research assistants to cover even a small number of countries for short periods of time.

What is the conclusion for future research strategies? Francis Castles proposes that we limit cross-national research to structural features and neglect the decision process because we cannot measure it reliably. Castles certainly recognizes the importance of the decision process, noting that it "is not that the agency is unimportant, but rather that it is frequently difficult to come to grips with its manifestation in individual choices, strategies and manoeuvres by means of the inherently generalizing methods of the social sciences." $\mathrm{He}$ argues that such generalizing methods are "quite impossible in the context

\footnotetext{
${ }^{9}$ Elazar, pp. 17-34.

${ }^{10}$ See for a discussion of these distortions: Germann and Steiner, "Comparing Decision Modes at the Country Level."

"Jürg Steiner, "Research Strategies Beyond Consociational Theory," The Journal of Politics 43 (November 1981): 1241-1250.
} 
of cross-national comparative studies, which seek to describe and explain highly aggregated patterns of political behaviour." Castles concludes that "this leaves the proper study of policy outcomes as the description of varying patterns of policy and the location of the structural relationships which underlie them."'12

Although we share Castle's view that it is virtually impossible to describe decision processes at the highly aggregated level of entire countries, his solution to neglect decision processes is unsatisfactory. Instead, one can lower the level of aggregation so as to compare not entire countries but specific issues. At this lower level of aggregation, it is feasible to describe the decision process with some reliability and validity. Elsewhere, we have described in detail the research strategies to be used if the units of analysis are specific issues. ${ }^{13}$ In the present context, it is important to note that the decision process about specific issues can be classified on a continuum from consociational to competitive and also on a continuum from federal to unitary. ${ }^{14}$ Combining the two dimensions, we can distinguish various admixtures of consociational and federal decision processes.

Changing the units of analysis from countries to issues not only has the advantage of higher reliability and validity, it also has theoretical benefits. In particular, it is easier to determine whether variation in the decision process has an effect on the policy outcome. One key question in the literature on federalism is whether federal decision processes benefit some groups more than unitary processes. In the consociational literature, the same question is raised for the distinction between consociational and competitive decisionmaking. To determine losers and winners is very difficult at the highly aggregated level of entire countries. Moreover, it is problematic to relate causally, in a convincing way, the policy outcome of an entire country to a particular pattern in the decision process. This task is much easier if the units of analysis are specific issues. At this level it is not too difficult to determine the winning and losing groups. It is also easier to see how particular aspects of the decision process could have a causal impact on the policy outcome.

Finally, working with issues rather than with countries allows us to increase the number of cases so that hypotheses can be subjected to sophisticated statistical tests. We can compare issues both between and within countries. This allows us to determine the importance of process versus structural variables, bringing us back to the basic theme of this article. With intra-

\footnotetext{
${ }^{12}$ Francis G. Castles, "How Does Politics Matter? Structure or Agency in the Determination of Public Policy Outcomes," European Journal of Political Research 9 (1981): 129.

${ }^{13} \mathrm{Jürg}$ Steiner, "Decision Process and Policy Outcome: An Attempt to Conceptualize the Problem at the Cross-National Level," European Journal of Political Research 11 (1983): 309-318.

${ }^{14} \mathrm{We}$ do not enter here the problem of the operational definition of the two dimensions. In an ongoing project, we characterize decision processes about specific issues with some additional dimensions. See, Jürg Steiner and Robert H. Dorff, "Decision Process and Policy Out come: An Attempt to Collect Data at the Cross-National Level" (Paper presented at the annual meeting of the American Political Science Association, Washington, D.C., 1984)
} 
country comparisons we can hold the institutional structure constant and examine whether variation in the decision process makes a difference. Perhaps structure is so important that the particular (in the words of Castles) "choices, strategies and manoeuvres" of the decisionmakers have no significant effect on the policy outcome. On the other hand, we can compare issues with the same decision process across countries with different structural arrangements. Here, we can see the possible effect of structural variation. Such intra- and inter-country comparisons would give us a good basis if we wish to advise politicians as to whether reforms should concentrate more on structural or process features. In Switzerland at the present time, it is often suggested that competition and federalism should be emphasized more. Would this primarily require changes in the institutional structures or would it be more important to encourage the decisionmakers to change their behavior within the given structural arrangements? Not only from a theoretical, but also from a practical perspective, it seems important to make such a distinction between structure and process. The main point of this article is that this distinction should be made more carefully in future discussions about consociationalism and federalism. 
